\title{
Assessment of Nutritional Status in Chronic Hepatic Patients at Ain Shams University Hospital
}

\author{
Amany M. Abdelhafez ${ }^{1}$, Azza E. Mohamed ${ }^{2}$, Hanan S. Ez-elarab ${ }^{1}$, Ghada O. Wassif ${ }^{1}$, \\ Yosra S Abd El-Ghaffar ${ }^{1}$
}

${ }^{1}$ Community, Environment and Occupational Medicine Department, ${ }^{2}$ Gastroenterology and Hepatology Department Faculty of Medicine, Ain Shams University

Received: March, 2017 Accepted: June, 2017

\begin{abstract}
Background: Malnutrition is prevalent in all forms of liver disease. The presence of malnutrition is associated with increased number of complications and increased short and long term mortality. Objectives: to assess the nutritional status of patients with chronic liver disease $\&$ identify the relationship between hepatic disease severity and degree of malnutrition. Methods: A cross sectional study, on a sample of chronic hepatic patients in Gastroenterology and Hepatology Department at Ain Shams University hospital. An interview questionnaire including socio-demographics, medical, surgical history and gastrointestinal symptoms had been completed. Nutritional status was assessed by using scored patient-generated-subjective global assessment (PG-SGA), anthropometric, functional parameters and Laboratory tests. Liver disease severity was assessed using Child Pugh score. Results: Sample of 161 patients, 104 from outpatient clinic and 57 from inpatients. Their mean age was $51.3 \pm 12.5$ years, $51.6 \%$ were males. They were $47 \%, 42 \%$ for class $\mathrm{A}, \mathrm{B}$ and $\mathrm{C}$ in consequence as for Child classification of liver disease. Assessment of malnutrition using Global PG-SGA revealed $16.8 \%$ were severely malnourished (PGSGA C), about half (50.9\%) were moderately malnourished (PG-SGA B), one third (32.3\%) were well nourished (PG-SGA A). About one quarter were moderately malnourished by either weight for age, MAC, TSF, MAMC or MAMA. There was a statistically significant difference between the three Child`s groups as regards PG-SGA total score and global rating and different anthropometric and functional methods. Conclusion \& recommendation: There was a high prevalence of malnutrition among chronic hepatic patients in Ain Shams University hospital. The degree of malnutrition increases as the severity of liver disease increase. Accordingly, proper nutritional screening and assessment should be done routinely to all chronic hepatic patients.
\end{abstract}

Key words: Nutritional status, Anthropometric assessment, hepatic patients, Malnutrition

Corresponding author : Yosra S Abd El-Ghaffar Email: dr_yosra_samir@hotmial.com

\section{Introduction:}

Chronic liver diseases remain as one of the most serious health problems worldwide, which may affect more than $10 \%$ of the world population ${ }^{1}$. In Egypt, approximately, 3.7 million persons have chronic HCV infection in the age group $15-59$ in $2015^{2}$. Malnutrition is found to be a common problem in patients with chronic hepatic diseases. The reported prevalence rates vary considerably according to the tool used to assess malnutrition, the type of patient population that was studied (i.e., hospitalized patients versus outpatients) and the severity of chronic hepatic disease. Many studies found that the prevalence rates ranges from $65 \%$ to $90 \%{ }^{3}$. Poor nutritional status in chronic 
hepatic patients is associated with many complications and may lead to increased morbidity and mortality rates ${ }^{4}$. Patients with chronic hepatic diseases who are malnourished have a higher rate of hepatic encephalopathy, infection, variceal bleeding and twice as likely to have refractory ascites ${ }^{5}$. Accordingly, early identification and treatment of malnutrition in these patients helps in prevention of these complications and improvement of the disease outcomes ${ }^{6}$. Subjective global assessment (SGA) is a rapid simple assessment method. It is a practical bedside tool recommended by European Society of Parenteral and Enteral Nutrition (ESPEN) for evaluating malnourished patients? ${ }^{7}$ One of the commonly used tools for assessment of malnutrition in chronic hepatic patients was the anthropometric measurements, weight and height, along with body mass index (BMI). Other anthropometric measurements include mid-arm circumference (MAC), triceps skin fold thickness (TSF), mid-arm muscle circumference (MAMC), mid-arm muscle area (MAMA) and hand grip strength test. Both mid-arm muscle circumference (MAMC) and mid-arm muscle area (MAMA) can be used to evaluate fat-free mass in nutritional assessment $^{8}$. A dynamometer is used to measure hand-grip strength which was found to be a helpful marker of nutritional status in chronic hepatic patients 9 .

The aim of this study was to assess the nutritional status of patients with chronic liver disease \& to identify the relationship between hepatic disease severity and degree of malnutrition.

\section{Methods}

A cross sectional study was conducted at Ain Shams university hospital - Egypt, during the period from January to June 2016. A convenience non random sample of chronic hepatic patients was recruited from the Gastroenterology and
Hepatology department including inpatients and outpatients. Inclusion criteria included patients above 18 years old of both sexes with documented chronic liver disease. Exclusion criteria: those with confirmed hepatocellular carcinoma, under sedation, critically ill or having any chronic debilitating disease.

Study tools: I) An interview questionnaire: consisted of two main sections, Section I: The sociodemographic data such as age, sex, occupation, residence, educational level, smoking status and alcohol consumption. Smoking history included pack-years smoked (average number of packs of cigarettes smoked per day multiplied by number of years smoked). Smoking status was presented as non-smokers, exsmokers and current smokers ${ }^{10}$. Also, patients were asked about the present medical conditions, disease symptoms and risk factors of hepatic disease e.g. blood transfusion, surgical and dentistry history. Section II: Rating of nutritional status by the Scored PG-SGA questionnaire- constructed by Ottery, $2000^{11}$. It contained four worksheets; points were given for each, then by summing up all the scores, a total PGSGA score was calculated. The risk of malnutrition increases with high total scores. A score 0-1 indicates that no intervention required. Patients with 2-3 score needs nutrition education. A score 4-8 requires nutrition intervention. A score $\geq 9$ suggests a serious need for nutrition intervention. In addition, each patient was classified by global rating as well-nourished (SGA A), moderately malnourished (SGA B) or severely malnourished (SGA C). II) Anthropometric assessment: 1- Weight: Weight was measured in kilograms. Dry weight for patients with ascites and/or edema was estimated by subtracting $5 \%$ of the patient's weight in the case of mild, $10 \%$ in moderate, and $15 \%$ in severe ascites. An additional 5\% was 
subtracted if there was lower limb edema $^{12}$. 2- Height: the readings were taken in $\mathrm{cm}^{10}$. 3- Body mass index: The dry-weight BMI $\left(\mathrm{kg} / \mathrm{m}^{2}\right)$ for each patient was calculated by the division of the estimated dry weight $(\mathrm{kg})$ by the square of the patient's height $\left(\mathrm{m}^{2}\right)^{12}$. Patients were categorized according to their dry BMI as: -Underweight BMI less than 18.5- Normal weight: BMI from 18.5 to 24.9- Overweight: BMI greater than or equal to 25; and -Obesity: BMI greater than or equal to $30^{13}$. 4- Mid- arm circumference (MAC): with a tape measure $^{14}$. 5- Triceps skinfold (TSF): Three readings were taken and mean was calculated $^{14}$. 6- Mid-arm muscle circumference (MAMC): was calculated from MAC and TST using a standard formula: MAMC = MAC $(3.1415 * \mathrm{TSF})^{15}$. 7- Mid-arm muscle area (MAMA): was calculated by the equation: MAMA $\left.=(\text { MAMC })^{2 / 12.56}\right)^{16}$. Percentiles of weight, height, MAC, TSF, MAMC and MAMA for age and sex were determined based on the tables developed by the National Health and Examination Survey (NHANS) ${ }^{15}$. Severe malnutrition was considered if the value of these measures is below the $5^{\text {th }}$ percentile, moderate malnutrition if their value is below $10^{\text {th }}$ percentile. When the value is above the $75^{\text {th }}$ percentile, the case was over nutrition ${ }^{16}$.

III) Functional assessment: Hand Grip Strength Test (HGS): was measured in kilogram force $(\mathrm{Kg} / \mathrm{F})$ with a hand dynamometer. Patients were asked to sit on a chair or on a bed, with the shoulder adducted, elbow flexed to a right angle and the forearm and wrist in the neutral position. Elbows were unsupported during HGS measurements. Patients were instructed to exert their maximum strength. Three measurements were made, and the maximum value was chosen as the HGS value ${ }^{17}$.

For women, HGS cutoff values were $20.2 \mathrm{Kg} / \mathrm{F}$ for the age group $18-44$ years;
For men of 45-64 years, $19.2 \mathrm{Kg} / \mathrm{F}$; 18 44 years, $41.7 \mathrm{Kg} / \mathrm{F}$; $45-64$ years, 37.9 $\mathrm{Kg} / \mathrm{F} ; \geq 65$ years, $30.2 \mathrm{Kg} / \mathrm{F}$.

Disease severity was classified according to the criteria proposed by Child-Pugh et al., $1964^{5}$ using five variables: serum levels of bilirubin and albumin, prothrombin time, ascites, and encephalopathy.

Table (A): Grading of liver disease severity using Child-Pugh score:

\begin{tabular}{lccc}
\hline \multicolumn{1}{c}{ POINTS } & $\mathbf{1}$ & $\mathbf{2}$ & $\mathbf{3}$ \\
\hline Encephalopathy & Absent & $1-2$ & $3-4$ \\
\hline Ascites & Absent & Mild & $\begin{array}{c}\text { moderate } \\
\text { to severe }\end{array}$ \\
\hline $\begin{array}{l}\text { Bilirubin } \\
(\mathrm{mg} / \mathrm{dl})\end{array}$ & $<2$ & $2-3$ & $>3$ \\
\hline Albumin $(\mathrm{g} / \mathrm{dl})$ & $>3.5$ & $2.8-3.5$ & $<2.8$ \\
\hline INR & $<1.7$ & $1.7-2.3$ & $>2.3$ \\
\hline
\end{tabular}

Then, the scores classified as: class A: 56 points - class B: 7-9 points and class C: $10-15$ points

Data Management and Analysis: A pilot study was conducted on 20 cases, not included in the final analysis. The collected data was revised, coded, tabulated and introduced to personal computer then analyzed using SPSS program (Statistical Package for Social Sciences) for windows Version 22.

Ethical Consideration: Approvals were taken from Ethical committee board of Faculty of Medicine and Ain Shams hospital administrative unit. Informed consent was taken from each participant, confidentiality and privacy were maintained.

\section{Results:}

Out of 161 studied chronic hepatic patients, the majority of the patients $(72.1 \%)$ were aged 45 or more. Their mean age was $51.3 \pm$ years. Males represented $51.6 \%$. Those living in rural areas were $55.9 \%$. About half of the studied cases $(47.8 \%)$ were illiterate. Most of the females $(96.1 \%)$ were house wives, while most of the males $(69.9 \%)$ were manual workers and $19.3 \%$ were unemployed or retired. Regarding special 
Table (1): General characteristics of the studied chronic hepatic patients

\begin{tabular}{|c|c|c|}
\hline \multirow{2}{*}{\multicolumn{3}{|c|}{$\begin{array}{l}\text { Patient characteristics } \\
\text { Age in Years }(n=161)\end{array}$}} \\
\hline & & \\
\hline - 18 & 10 & 6.2 \\
\hline - $30-$ & 35 & 21.7 \\
\hline - $45-$ & 70 & 43.5 \\
\hline - 60 or more & 46 & 28.6 \\
\hline Mean $\pm S D$ & \multicolumn{2}{|l|}{$51.3 \pm 12.49$} \\
\hline \multicolumn{3}{|l|}{ Gender $(n=161)$} \\
\hline - Male & 83 & 51.6 \\
\hline - Female & 78 & 48.4 \\
\hline \multicolumn{3}{|l|}{ Residence (n=161) } \\
\hline - Rural & 90 & 55.9 \\
\hline - Urban & 71 & 44.1 \\
\hline \multicolumn{3}{|l|}{ Education $(n=161)$} \\
\hline - Illiterate & 77 & 47.8 \\
\hline - Read \& write/primary & 31 & 19.3 \\
\hline - Preparatory & 18 & 11.2 \\
\hline - Secondary & 22 & 13.6 \\
\hline - University & 13 & 8.1 \\
\hline \multicolumn{3}{|l|}{$\begin{array}{l}\text { Occupation among females } \\
(n=78)\end{array}$} \\
\hline - Unemployed $\backslash$ retired & 1 & 1.3 \\
\hline - House wife & 75 & 96.1 \\
\hline - Employee & 2 & 2.6 \\
\hline \multicolumn{3}{|l|}{$\begin{array}{l}\begin{array}{l}\text { Occupation among males } \\
(\mathrm{n}=83)\end{array} \\
\end{array}$} \\
\hline - Unemployed $\backslash$ retired & 16 & 19.3 \\
\hline - Employee & 9 & 10.8 \\
\hline - Manual worker & 58 & 69.9 \\
\hline \multicolumn{3}{|l|}{ Smoking $(\mathrm{n}=161)$} \\
\hline - Current smokers & 39 & 24.2 \\
\hline - Ex-smokers & 21 & 13 \\
\hline - Never smoke & 101 & 62.8 \\
\hline \multicolumn{3}{|l|}{ Tobacco exposure (n=161) } \\
\hline - 0 packs*years & 101 & 62.8 \\
\hline $\begin{array}{l}\text { - }<20 \text { packs*years (light } \\
\text { smoker) }\end{array}$ & 30 & 18.6 \\
\hline $\begin{array}{l}\text { - } \geq 20 \text { packs*years (heavy } \\
\text { smoker) }\end{array}$ & 30 & 18.6 \\
\hline
\end{tabular}

Alcohol consumption ( $n=161)$

- Ever $4 \quad 2.5$

- Never $157 \quad 97.5$

habits of medical importance of the studied patients, nearly one quarter of the studied patients $(24.2 \%)$ were currents smokers, $13 \%$ were ex-smokers. $18.6 \%$ of the studied patients smoked 20 pack*year or more (i.e. heavy smokers). Only $2.5 \%$ of the studied patients were drinking alcohol (Table 1). Past history of diseases, $65.8 \%$ had diabetes mellitus while $62 \%$ were hypertensive. The most common cause of
Table (2): Correlation between functional and anthropometric variables with PGSGA score among the studied chronic hepatic patients

\begin{tabular}{lll}
\hline Variables & \multicolumn{1}{c}{ R } & \multicolumn{1}{c}{ P value } \\
HGS & -0.349 & $0.000^{* *}$ \\
BMI & -0.23 & $0.003^{* *}$ \\
MAC & -0.182 & $0.021^{*}$ \\
TSF & -0.113 & 0.152 \\
MAMC & -0.169 & $0.032^{*}$ \\
MAMA & -0.153 & 0.052 \\
\hline
\end{tabular}

(*) Statistically significant at $P<0.05$ (**)statistically significant at $P<0.01$ chronic liver disease was hepatitis C infection $(81.4 \%)$, followed by hepatitis B infection (8.1\%). Out of 119 with GIT symptoms in the previous two weeks, anorexia was the most common symptom (49.6\%), followed by constipation and abdominal pain with the same percentage (30.2\%), 29.4\% suffered from feeling full quickly. Vomiting was reported by $27.7 \%$ of them and diarrhea by $12.6 \%$. More than half reported a decrease in their weight in the previous two weeks. On the other hand, 5.6\% reported gaining weight. Assessment of malnutrition using Global PG-SGA revealed $16.8 \%$ were severely malnourished (PG-SGA C), about half $(50.9 \%)$ were moderately malnourished (PG-SGA B), one third $(32.3 \%)$ were well nourished (PG-SGA A) (Figure 1). Among the studied chronic hepatic patients, $25.5 \%, 28.6 \%$,

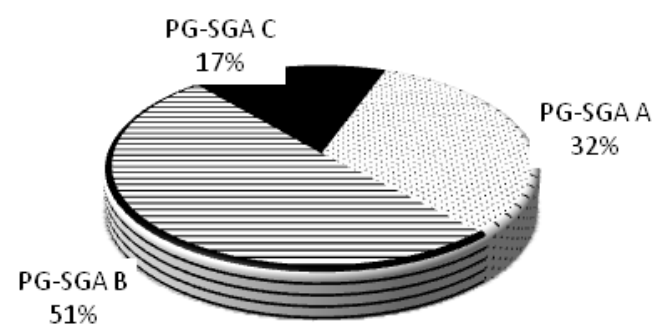

Figure (1): Assessment of malnutrition in the studied chronic hepatic patients using Global PG-SGA

$22.4 \%, 23.6 \%, 23 \%$ of the patients were moderately malnourished $\quad\left(<10^{\text {th }}\right.$ percentile) according to weight for age, MAC, TSF, MAMC, and MAMA respectively. And that, $18.6 \%, 21.7 \%$, 
Table (3): Nutritional assessment results by the total PG-SGA score, anthropometric and functional measures and the Global PG- SGA rating among hepatic disease severity categories

\begin{tabular}{lcccccc}
\hline & $\begin{array}{c}\text { Child A } \\
\mathbf{n}=\mathbf{7 6}\end{array}$ & $\begin{array}{c}\text { Child B } \\
\mathbf{n = 6 7}\end{array}$ & $\begin{array}{c}\text { Child C } \\
\mathbf{n = 1 8}\end{array}$ & ANOVA & P value & $\begin{array}{c}\text { Post } \\
\text { Hoc } \\
\text { Test }\end{array}$ \\
\cline { 2 - 6 } Mean \pm SD & Mean \pm SD & $\begin{array}{c}\text { Mean } \\
\text { SD }\end{array}$ & \pm & &
\end{tabular}

$\begin{array}{ll}\text { (*) Statistically significant at } P<0.05 \quad(* *) \text { Statistically significant at } P<0.01 & \text { (\#) }\end{array}$

(\#) Fisher Exact test was used as $20 \%$ of cells or more have expected count less than 5

$19.3 \%, 20.5 \%, 21.7 \%\left(<5^{\text {th }}\right.$ percentile $), \quad$ There is a negative correlation between respectively, indicating severely malnourished. There is diversity in the percentage of patients predicted as having moderate malnutrition by different nutritional assessment methods; where $50.9 \%$ of the studied patients as moderate malnutrition by PG-SGA, then (28.6\%) by MAC, $(25.5 \%)$ by weight for age, $(24.8 \%)$ by HGS, MAMC by $(23.6 \%),(23 \%)$ by MAMA, $(22.4 \%)$ by TSF, (12. \%) by BMI. On the other hand, by comparing the percent of hepatic patients predicted as severe malnutrition, the highest percent $(87.6 \%)$ by HGS( $28 \%$ ) by either MAC and MAMA detected severe malnourished patients. $20.5 \%, 19.3 \%, 18.6 \%, 17 \%$ of the patients had severe malnutrition according to MAMC, TSF, weight for age, PG-SGA respectively. None of the patients had severe malnutrition by using BMI (Figure 2).

PG-SGA score and HGS and BMI (P $<0.01)$. Also, there is a negative correlation between PG-SGA score and MAC and MAMC ( $P<0.05)$. On the other hand, there is no significant correlation between PG-SGA score and TSF and MAMA (P >0.05). (Table 2)

Studying the relationship between hepatic disease severity and malnutrition assessed by total PG-SGA score shows that the more sever the hepatic disease, the higher the PG-SGA score. As regards total PG-SGA score, the mean score for Child $\mathrm{C}$ group was significantly higher than that for Child A and B ( $\mathrm{P}$ value < $0.01)$. The relationship between hepatic disease severity and malnutrition assessed by the mean of different anthropometric and functional measures was studied. There was a statistically significant difference between the three Child groups as regards weight and HGS 


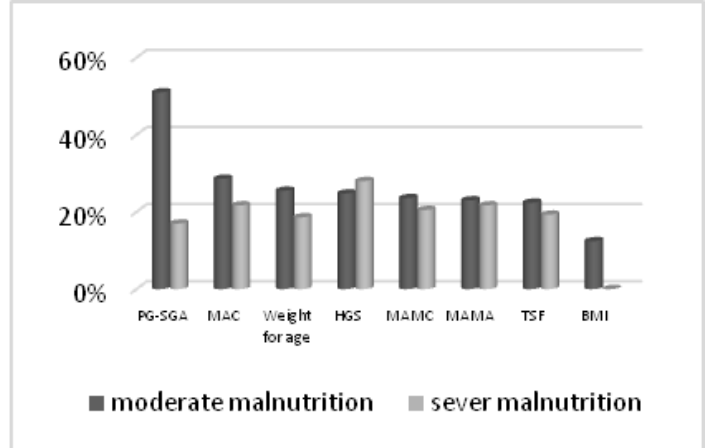

Figure (2): Percentage of malnutrition among studied chronic hepatic patients according to different nutritional assessment methods

test $(\mathrm{P}<0.01)$. The means of weight, BMI, HGS test, MAC, TSF, MAMC and MAMA for Child $C$ were lower than that for Child A and B. In addition, there was a statistically significant difference between the three Child groups as regards MAC and TSF ( $\mathrm{P}<0.05)$. Regarding mid-arm circumference, there was a highly statistically significant difference between Child A group \& Child $\mathrm{C}$ group $(\mathrm{P}<0.01)$ and a statistically significant difference between Child B group \& Child C group also, triceps skinfold thickness, there was a statistically significant difference between Child A group \& Child $\mathrm{C}$ group $(\mathrm{P}<0.05)$ (Table 3).

\section{Discussion:}

Malnutrition in all forms of liver disease is associated with higher rates of mortality and morbidity but it is often under-recognized and under-treated despite the fact that appropriate treatment can improve outcomes ${ }^{18}$. Concerning nutritional assessment of the studied chronic hepatic patients, patient generated subjective global assessment (SGA) is a rapid simple assessment method, recommended by ESPEN as a practical bedside tool for evaluating malnourished patients ${ }^{7}$. The scored PGSGA is a another development of the PGSGA that contains a numerical score in addition to providing a global rating of nutritional status ${ }^{11}$. In the present study we used the scored PG-SGA on 161 patients and results revealed that near half of them $(50.9 \%)$ had moderate malnutrition (SGA-B) and $16.8 \%$ had severe malnutrition (SGA-C). This result is similar to Yao et al., 2016 ${ }^{19}$ who carried out a study on 120 patients with HBV or HCV-related cirrhosis and found that $48.3 \%$ were moderately malnourished (SGA-B), and $11.7 \%$ severely malnourished (SGA-C). Also, Ferreira et al., $2011^{20}$ performed a study on patients older than 20 years who were on the waiting list for liver transplantation in a liver transplantation outpatient clinic in Brazil and found that malnutrition was present in $74.7 \%$ of the patients; $53.8 \%$ were moderately and $20.9 \%$ were severely malnourished. This result is inconsistent with Monsef et al., $2014^{21}$ who reported that, by using SGA, malnutrition was present in $100 \%$ of the patients, and of these, $40 \%$ were moderately and $60 \%$ were severely malnourished. Also Yosry et al., 2014 ${ }^{22}$ who performed a study on 30 Egyptian patients found that $16(53.3 \%)$ were moderately malnourished and 14 (46.7\%) were severely malnourished patients. Both Monsef et al., $2014^{21}$ and Yosry et al., 2014 22 studied patients with end stage liver disease before liver transplantation; accordingly they all had a degree of malnutrition. Regarding the total score of PG-SGA of the chronic hepatic patients, in the present study, it was observed that $11.2 \%$ of the patients had total score 0-1 with no intervention required. In addition, $14.9 \%$ had total score 2-3 requiring patient and family education with pharmacological intervention. Patients required intervention by dietitian, in conjunction with nurse or physician with 4-8 total score were $29.2 \%$. On the other hand, nearly half of the patients $(44.7 \%)$ had high total PG-SGA score $(\geq 9)$ indicating a critical need for improved symptom management and/or nutrient intervention options.Severity of liver disease was assessed by child-pugh classification and 
the differences of nutritional status in Child A, B and C groups were assessed by different nutritional assessment tools. Generally, Malnutrition prevalence increased with the more advanced stages of disease. In the present study, there was highly significant relationship between malnutrition assessed by PG-SGA score and progression of liver disease assessed by Child Pugh score. Similar study was done by Ferreira et al., $2011^{20}$ who confirmed that PG-SGA score increases with progress of liver disease. Also, Ibrahim et al., $2015^{23}$ who performed a study on ninety Egyptian patients with HCV related chronic liver disease, agreed with that result. As regards Global PG- SGA rating, we found that more than half of Child A patients have PG-SGA rate $A$, while the remaining have PG-SGA rate $B$ and no cases have PG-SGA rate $C$. On the other hand, in Child $\mathrm{C}$ patients, about two thirds of them have severe malnutrition with PGSGA rate C. This result agrees with Saleh et al., 2014 ${ }^{24}$ in AL-Azhar University Hospital, Egypt. They found a tendency towards a higher proportion of poor nutritional status, assessed by SGA, in patients with Child-Pugh $\mathrm{B}$ \& $\mathrm{C}$ compared to Child-Pugh A. Also these findings agrees with Tai et al., 2010 25 who found a higher proportion of bad nutritional status (SGA rate $\mathrm{C}$ ) in Child $\mathrm{C}$ patients compared to Child B patients. Anthropometric measurements are reasonably accurate bedside tools for detection of malnourished status of cirrhotic patients and skinfold anthropometry has been considered as the best indirect method to assess body fat stores in these patients. The present study found that the mean BMI was $28.26 \mathrm{Kg} / \mathrm{m}^{2}$, mean MAC was $31.81 \mathrm{~cm}$, mean TSF was $2.12 \mathrm{~cm}$ and mean MAMC was $25.12 \mathrm{~cm}$. These results, approximately, agree with Yosry et al., $2014^{22}$ who found that the mean BMI was $28.4 \mathrm{Kg} / \mathrm{m}^{2}$, mean MAC was 26.56 $\mathrm{cm}$ and mean TSF was $2.25 \mathrm{~cm}$. Another study carried out by Fernandes et al., $2012^{26}$ on 129 cirrhotic patients agreed with the mean MAMC $(25 \mathrm{~cm})$. Regarding body mass index (BMI), the present study showed that only $12.4 \%$ had abnormally low BMI. This result agrees with Qinggang et al., $2015^{27}$ who reported that $11.6 \%$ were underweight. On the other hand, Butt et al., $2009^{(28)}$ found that a higher percent $(32 \%)$ of the studied patients in a Military Hospital had BMI $<18.5 \mathrm{Kg} / \mathrm{m}^{2}$. By using hand grip strength test, the current study found that about half of the studied chronic hepatic patients (percent of 52.8\%) were malnourished, however; the percentage of malnutrition was higher in a study carried out by Fernandes et al., 2012 which is $69.3 \%$ of the studied cirrhotic patients. While in another study carried out by Ferreira et al., $2011^{\text {(20) }}$ the percentage of malnutrition was $80.8 \%$ in patients waiting for liver transplantation.

Nardi et al. (29) stated that, skin fold anthropometry is considered a useful technique for assessment of body composition in patients with chronic liver disease. It is value in detecting mild or moderate signs of malnutrition, which are difficult to recognize clinically. Likewise of Caregaro et al. ${ }^{30}$ stated that, because of limitations of other nutritional indexes, skin fold anthropometry represents-at present-the most reliable clinical measure of nutritional status in patients with chronic liver disease.

Our study showed that $20.5 \%$ and $19.3 \%$ were severely malnourished (MAMC and $\mathrm{TSF}<5^{\text {th }}$ percentile), respectively. Also, $23.6 \%$ and $22.4 \%$ had moderate malnutrition (MAMC and TSF $<10^{\text {th }}$ percentile), respectively. On the other hand, $31.1 \%$ and $46 \%$ had over-nutrition with MAMC and TSF $>75$ th percentile, respectively. These results are lower than Rana et al., $2016^{31}$ who studied cirrhotic patients in Bangladesh and found that $34 \%$ of patients had severe malnutrition as determined by MAMC and/or TSF < 5 th percentile and $20 \%$ had moderate
No. 2

April

2018 
malnutrition (MAMC and/or TSF < 10th percentile). Twenty-six percent of patients were over-nourished (MAMC and/or TSF $>75$ th percentile). While Tai et al., $2010{ }^{25}$ who studied 36 Malaysian patients with compensated cirrhosis, found a higher percent of sever malnourished patients $(50 \%)$ with MAMC $<5$ th percentile, this discrepancy because their study were done on decompensated cirrhotic patients.

Monsef et al., $2014^{21}$ found that the lowest percent of malnutrition among all assessment methods was BMI. Current study results revealed that malnutrition ranged from $87.6 \%$ to $12.4 \%$ according to the different methods of assessment. Monsef et al., $2014^{21}$ also found a wide range between prevalence of malnutrition assessed by different methods where it ranged from $7 \%$ (by BMI) to $100 \%$ (by SGA).

Regarding the relationship between chronic hepatic disease severity and malnutrition assessed by different anthropometric and functional tools for Child $\mathrm{C}$ were lower than that for Child A and $\mathrm{B}$ in the current study. There was a statistically significant difference between the three Child groups as regards weight, HGS test, MAC and TSF. This result is consistent with a prospective Indian study by Singh et al., $2013^{32}$ in an outpatient unit on patients with compensated and decompensated liver disease, and revealed that, except for BMI, Child C patients had significantly lower anthropometric measurements compared to Child A \& B cases. Butt et al., $2009^{28}$ also found that Child C patients showed significantly lower mean BMI. In addition, Monsef et al., $2014^{21}$ found that dynamometry and muscle mass assessed by MAMC were different between Child-Pugh classes. Fernandes et al., $2012{ }^{26}$ demonstrated that hand grip strength test didn't show statistically significant relation with the Child-Pugh classes. Rana et al., $2016^{30}$ found that percentage of severely malnourished patients based on MAMC and TSF increased with severity of liver disease. Also, Ferreira et al., 201120 observed that the loss of muscle mass assessed by MAC was associated with severity of disease assessed by Child Pugh criteria which is consistent with results of the current study.

The correlation between anthropometric variables \& PG-SGA score in the present study showed that there is negative correlation between most anthropometric variables $(\mathrm{P}<0.05)$ except with TSF and MAMA ( $>0.05)$. These findings agree with Monsef et al., $2014^{21}$ who found that there is negative correlation between most anthropometric variables \& SGA $(p<0.01)$.

\section{Conclusions and recommendations:}

The study concluded that among chronic hepatic patients in Ain Shams University hospital, the majority were malnourished by using PG- SGA. In addition, both PGSGA and anthropometric parameters are important methods for nutritional assessment of chronic liver disease patients. It was found that degree of malnutrition was correlated with the severity of liver disease. Thus we recommend, routine nutritional screening and assessment to all chronic hepatic patients, PG- SGA is a simple and accurate nutritional assessment tool and suitable for chronic hepatic patients and the lack of a national reference database of anthropometric measurements of the Egyptian population raises the need for population based anthropometric surveys.

\section{References:}

1. Vong, S., \& Bell, B. P. (2004). Chronic liver disease mortality in the United States, 1990-1998. Hepatology, 39(2), 476-483.

2. Kandeel, A., Genedy, M., El Refai, S., Funk, A. L., Fontanet, A., \& Talaat, M. (2017). The prevalence of hepatitis C virus infection in Egypt 2015: 
implications for future policy on prevention and treatment. Liver International, 37(1), 45-53.

3. Patton, H. M. (2012). Nutritional Assessment of Patients with Chronic Liver Disease. Gastroenterology \& hepatology, 8(10), 687.

4. Alberino, F., Gatta, A., Amodio, P., Merkel, C., Di Pascoli, L., Boffo, G., \& Caregaro, L. (2001). Nutrition and survival in patients with liver cirrhosis. Nutrition, 17(6), 445-450.

5. Lautz, H., Selberg, O., Körber, J., Bürger, M., \& Müller, M. (1992). Protein-calorie malnutrition in liver cirrhosis. The clinical investigator, 70(6), 478-486.

6. Bémeur, C., \& Butterworth, R. F. (2015). Nutrition in the Management of Cirrhosis and its Neurological Complications. Journal of clinical and experimental hepatology, 5, S131-S140.

7. Plauth, M., Cabre, E., Riggio, O., Assis-Camilo, M., Pirlich, M., Kondrup, J., Ferenci, P., Holm, E., Vom Dahl, S., \& Müller, M. (2006). ESPEN guidelines on enteral nutrition: liver disease. Clinical nutrition, 25(2), 285-294.

8. Madden, A., \& Smith, S. (2014). Body composition and morphological assessment of nutritional status in adults: a review of anthropometric variables. Journal of Human Nutrition and Dietetics, 29, 1.

9. Da Silveira, T. R. (2005). Comparison between handgrip strength, subjective global assessment, and prognostic nutritional index in assessing malnutrition and predicting clinical outcome in cirrhotic outpatients. Nutrition, 21(2), 113-117.

10. Pennsylvania department of health (2010). Anthropometric Training manual, Division of Women, Infants and Children (WIC) (pp. 7-11).

11. Ottery, F. (2000). Patient-generated subjective global assessment. The clinical guide to oncology nutrition, 1123.
12. Tandon, P., Ney, M., Irwin, I., Ma, M. M., Gramlich, L., Bain, V. G., Esfandiari, N., Baracos, V., MontanoLoza, A. J., \& Myers, R. P. (2012). Severe muscle depletion in patients on the liver transplant wait list: its prevalence and independent prognostic value. Liver Transplantation, 18(10), 1209-1216.

13. World Health Organization (WHO), (2016). Body mass index. Available at: http://www.euro.who.int/en/health-

topics/disease-prevention/nutrition/ahealthy-lifestyle/body-mass-index-bmi 14. Fryar, C. D., Gu, Q., \& Ogden, C. L. (2012). Anthropometric reference data for children and adults: United States, 2007-2010. Vital and health statistics. Series 11, Data from the national health survey (252), 1-48.

15. Jones, J. M. (2004). Reliability of nutritional screening and assessment tools. Nutrition, 20(3), 307-311.

16. Frisancho, A. R. (1990). Anthropometric standards for the assessment of growth and nutritional status: University of Michigan Press.

17. Guerra, R., Fonseca, I., Pichel, F., Restivo, M., \& Amaral, T. (2014). Handgrip strength cutoff values for undernutrition screening at hospital admission. European journal of clinical nutrition, 68(12), 1315-1321.

18. John Saunders, Anna Brian, Mark Wright, Mike Stroud (2010). Malnutrition and nutrition support in patients with liver disease. Frontline Gastroenterology; 1:105-111

19. Yao J, Chang L, Yuan L, Duan Z (2016). Nutrition status and small intestinal bacterial overgrowth in patients with virus - related cirrhosis. Asia Pac J Clin Nutr; 25(2):283-291.

20. Ferreira L. G., Anastácio L. R., Lima A. S. and Correia M. I.T.D. (2011). Assessment of nutritional status of patients waiting for liver transplantation. Clinical Transplantation, 25: 248-254.

21. Waheed A. Monsef, Ibrahim Mostafa, Doaa Zaky (2014). Assessment 
of the Nutritional Status of the Egyptian Patient with End Stage Liver Disease Prior to Liver Transplantation. Open Journal of Gastroenterology; 4, 159-169

22. Ayman Yosry, Dalia Omran, Mohamad Said, Waleed Fouad \& Osama Fekry (2014). Impact of nutritional status of Egyptian patients with end-stage liver disease on their outcomes after living donor liver transplantation. Journal of Digestive Diseases; 15; 321-326

23. Ibrahim AA, Mahmoud Salem HE, Zaky DZ, El-Sayed EA, Hamed AM, Kazem YMI (2015). Dietary Patterns in Egyptian Patients with Chronic Hepatitis C Related Liver Disease: A CrossSectional Study. Journal of Liver 4:176.

24. Medhat A Saleh, Hamdy M Mustafa , Khaled A Eid, Mona M A Soliman and Hamada H Sultan (2014). Assessment of nutritional status of patients with chronic liver diseases admitted to gastroenterology department Al- Azhar University Hospital, Assuit. Al- Azhar Assiut Medical Journal; 12 (3), 89-110 25. Mei-Ling $S$ Tai, Khean-Lee Goh, Siti Hawa Mohd-Taib, Sanjay Rampal, and Sanjiv Mahadeva (2010). Anthropometric, biochemical and clinical assessment of malnutrition in Malaysian patients with advanced cirrhosis. Nutrition Journal; 9: 27.

26. Fernandes, Sabrina Alves, Bassani, Lilian, Nunes, Flávia Feijó, Aydos, Maria Eugênia Deutrich, Alves,
Alexandro Vaesken, \& Marroni, Cláudio Augusto. (2012). Nutritional assessment in patients with cirrhosis. Arquivos de Gastroenterologia, 49(1), 19-27

27. Qinggang Li, Hui Xing, Dan Liu, Hui Li (2015). Negative impact of low body mass index on liver cirrhosis patients with hepatocellular carcinoma. World Journal of Surgical Oncology; 13(1), 1.

28. Shaheen Butt, Parvez Ahmed, Perveen Liaqat and Hajira Ahmad (2009). A Study of Malnutrition among Chronic Liver Disease Patients. Pakistan Journal of Nutrition, 8: 1465-1471.

29. Nardi, M., Ognana, G., Schiavo, G., Caregaro, L. (2009). Nutritional support in liver cirrhosis, Journal of Nutritional Therapy and Metabolism, (27), 155-163. 30. Caregaro L, Alberino F, Amodio P (1996). Malnutrition in alcoholic and virus-related cirrhosis. Am J Clin Nutr;63:602-9.

31. Rana MA, Faisal MA, Karim ME, Siddique AR, Ahmed DS, Raihan ASMA (2016). Assessment of Malnutrition in Cirrhotic Patients. Bangladesh Journal of Medical Science; Vol. 15 No. 02.

32. Singh N, Choudhary JK, Srivastava M, Tripathi MK, Rungta S, Singh SK, Jain AK, Dixit VK (2013). Nutritional and Clinical Profile Of Patients In Different Stages Of Alcoholic And Virus Related Liver Disease: An Indian Perspective. Gastroenterology;4(12) 